\title{
Augusto e historiografías periféricas: estudio de la figura de Augusto en la historiografía catalana*
}

Jordi Cortadella Morral

Universitat Autònoma de Barcelona UAB

Jordi.Cortadella@uab.cat

Albert Masat Barcina

Universitat Autònoma de Barcelona UAB

Albert.Masat@e-campus.uab.cat

Fecha recepción 09.01.2017 / Fecha aceptación 09.03.2017

\section{Resumen}

Este trabajo es un estudio sobre la figura de Augusto en la historiografía catalana, desde los cronicones monásticos del siglo XII hasta las reivindicaciones nacionalistas del siglo XX. En el recorrido por este largo período veremos cómo Augusto pasa de ser parte de un mero sistema de datación, relacionado con el nacimiento de Cristo, a convertirse en una seña de identidad debido a la circunstancia (fortuita) de residir por un tiempo en Tarraco, y por tanto, gobernar su Imperio desde tierras catalanas. En el camino, Augusto atraviesa por momentos tanto de completo silencio historiográfico

\begin{abstract}
This paper studies the figure of Augustus in Catalan historiography, from the monastic chronicles of the 12 th century to the 20th century nationalistic claims. The survey of this long period allows us to see how Augustus goes from being part of a system of dating, relating to the birth of Christ, to becoming a symbol of identity, due to the (fortuitous) circumstance of having stayed briefly in Tarraco, ruling his empire from Catalonia. During this process, Augustus experienced both moments of absolute historiographical silence and of complete disdain. However, he finally reached a
\end{abstract}

* MINECO HAR2012-31736 
Monográfico | Augusto e historiografías periféricas: estudio de la figura de Augusto en la historiografía catalana

como de absoluto desprecio hasta alcanzar aquella consideración atemporal y acrítica tan propia de lo clásico. La cuestión a dilucidar es si este tratamiento del personaje se realiza en paralelo a la historiografía oficial española o en contraposición a ella.

\section{Palabras clave}

Augusto, historiografía catalana timeless and uncritical consideration typical of the classics. The key element is to establish whether this treatment of his character is performed in parallel to the official Spanish historiography or opposed to it.

Key words

Augustus, Catalan historiography. 
No QUERRÍAMOS INICIAR ESTE ARTículo sin un breve comentario sobre el concepto de «historiografías periféricas» que, evidentemente, existe solo en la medida que se concibe una «historiografía central». En la Edad Media y en buena parte de la Época Moderna, la historiografía catalana o de la corona catalano-aragonesa fue tan central como la historiografía castellana y, a su vez, ambas tubieron sus «periferias», pues generaron una historiografía subsidiaria, que dependía o se oponía a la oficial, es decir, la generada por los círculos cortesanos. En este sentido, la historiografía catalana es ciertamente dependiente o, en algunos casos, contrapuesta a la historiografía española sólo en determinadas épocas y circunstancias, estrechamente vinculadas con las vicisitudes políticas y las relaciones de poder. Augusto, en estas «historiografías periféricas», no deja de ser un elemento reivindicativo más de las glorias de antaño frente a las incertidumbres del presente.

\section{Augusto en Tarraco}

En los años 26-25 aC Augusto, el flamante princeps, residió en Tarraco recuperándose de una enfermedad que le obligó a abandonar el frente cántabro (Dio., 53.25.7). En Tarraco, Augusto guardó convalecencia y recibió las atenciones del famoso médico Antonio Musa, el cual le aplicó un tratamiento de baños fríos que, según Suetonio (Aug. 81, 1), resultó muy efectivo. Desde Tarraco, Augusto dirigió el Imperio, convirtiendo la ciudad, por un tiempo, en el máximo centro de poder político después de Roma. Allí el Imperator ejerció sus consulados octavo y noveno (Suet., Aug. 26.6) y dio audiencia a varias delegaciones: una de la ciudad de Mitilene (AP, 7.376 Crin; $I G$, XII.2.44), otra del rey de los partos y una tercera procedente de la India (Oros., 6.21.19-21), que posiblemente no fueron las únicas. Durante su estancia en Tarraco, la ciudad le dedicó un altar (Quint., Inst. 6.3.77), que aparece representado en las monedas tarraconenses de época de Tiberio y que constituye la primera prueba clara de la presencia del culto imperial en Tarraco. Tácito nos informa (Ann. 1.78.1) que en el año $15 \mathrm{dC}$ una asamblea de hispanos solicitó al nuevo emperador Tiberio la autorización para erigir un templo en honor del divinizado Augusto en Tarraco. 
Todas estas noticias recogidas por las fuentes clásicas son otras tantas razones que animaron a los historiadores catalanes a incluir a Augusto en la historiografía catalana, pero con criterios y finalidades diferentes según la época. ${ }^{1}$

\section{Augusto en la historiografía condal (siglos XII-XIII)}

La desvinculación de los condes catalanes del poder real franco creó, en el ámbito historiográfico, la necesidad de autodefinirse. Las anotaciones posteriores al año 985 incluidas en los cronicones catalanes son una prueba de ello y las Gesta Comitum la culminación. ${ }^{2}$

El Chronicon Rivipullense II es la primera referencia que tenemos sobre Augusto en la historiografía catalana. Proveniente del scriptorium del Monasterio de Ripoll, se trata de un listado de fechas y hechos relacionados que abarcan, en la primera parte, desde el nacimiento de Cristo hasta el año 659. Estos cronicones tenían como patrón, en especial por lo que se refiere a las noticias de los primeros siglos de la era cristiana, los pasajes más escuetos de los cronicones de Eusebio (conocido en Occidente a través de Jerónimo), de Próspero de Aquitania y de Beda. Los fragmentos en que se menciona a Augusto son los siguientes:

I.Anno quarto regni Octauiani. Era ab ipso constituta est. Anni quadragesimo secundo imperi Octauiani Augusti natus est Iesus Chisti filius dei in Betleem inde esse Marie uirgine subcuris imperio LX et XX ebdomede in Daniele scripta complentur.

V.Herodes ab Octauiano Iudeam missus primus ibi ex gratibus regnauit.

XXXVI.Hoc anno cepit indici qui fuit XXX.VIII regni Octauiani.

XXXVIII.1. Imperio Octauiani XL.II.LXX.VII ebdomadus in Danielo scripte completur Iesus Christus ex uirginum nascitur.

LIII.15. Finit regnum Octauiani LVI annorum. ${ }^{3}$

Como puede observarse, en el cronicón conviven dos sistemas de datación: la Era Hispánica (en núm. romanos) y el nacimiento de Cristo (en cifras arábicas). La Era Hispánica fue un sistema de datación usado en la Península a partir del siglo V. Comenzaba en el 38 aC, año en el que, según la tradición, se adoptó el calendario Juliano. En Cataluña, la datación según la Era Hispánica fue abolida oficialmente a finales del siglo XII. El hecho de que este cronicón utilice los dos sistemas de datación nos da una pista sobre la utilidad de estos textos,

1. Para una visión de conjunto sobre la historiografía catalana, véase: A. Balcells (ed.), Història de la historiografía catalana, Institut d'Estudis Catalans, Barcelona, 2004; A. Simon Tarrés (dir.), Diccionari d'historiografia catalana, Barcelona, 2003.

2. Para la historiografía de este período, véase: J. Alturo, "La historiografia catalana del període primitiu", y A. G. Hauf, "Les cròniques catalanes medievals. Notes entorn a la seva intencionalitat", en A. Balcells (ed.), Història de la historiografía catalana, Barcelona, 2004, 19-38 y 39-75.

3. Mn. 588, Biblioteca Universidad Barcelona. 
pues a través de ellos se podían relacionar correctamente hechos o documentos con sistemas cronológicos diferentes. ${ }^{4}$

En las Gesta Comitum Barcinonensium (segunda mitad del siglo XII), que de hecho es la primera historia oficial catalana, no figura la historia anterior a Wifredo el Velloso, fundador de la dinastía condal catalana, según la tradición. Augusto tampoco aparece referenciado en las cuatro grandes crónicas catalanas (Jaime I, Muntaner, Desclot y Pedro el Ceremonioso), todas ellas escritas entre los siglos XIII y XIV, ya que se trata de narraciones dinásticas, centradas en relatar los sucesos de su época, aunque en la de Bernat Desclot (finales del siglo XIII) y Ramon Muntaner (primera mitad del siglo XIV) se comparan las victorias de rey Pedro III de Aragón (Pedro el Grande) con las hazañas de Alejandro Magno, y no con las de Augusto. ${ }^{5}$

Tampoco se hace mención de Augusto en las Cròniques dels reis d'Aragó e comtes de Barcelona (más conocida como Crónica de San Juan de la Peña) de mediados del siglo $\mathrm{XIV}$, que de hecho significaba el entronque de las Gesta Comitum Barcinonensium con la historia primitiva peninsular, en la versión dada por Rodrigo Jiménez de Rada (Historia de rebus Hispaniae sive Historia gótica). Para tener noticias de las vicisitudes de Augusto, en la Península y fuera de ella, debemos conformarnos con las breves anotaciones que aparecen en las crónicas universales catalanas de los siglos XIII al XV ${ }^{6}$, como el Compendi historial de Jaume Domènec o la anónima Flos Mundi, que siguen como modelo la Chronique latine de Guillermo de Nangís.

\section{El nuevo Augusto de la historiografía dinástica (siglos XIV-XV)}

En cambio, como no podía ser de otra manera, Augusto aparece con perfil propio en la producción historiográfica cercana al Humanismo (no estrictamente humanista, si se me permite el matiz) de Juan Fernández de Heredia (c. 1310-1396). ${ }^{7}$ En su Gran crónica de los conquistadores, el gran Maestre de la Orden de San Juan de Jerusalén al servicio de Pedro IV de Aragón recopila treinta y seis biografías divididas en dos partes. La primera incluye a diecisiete personajes de la Antigüedad, ${ }^{8}$ mientras que la segunda parte recoge desde emperado-

4. M. Coll i Alentorn, "La historiografia catalana en el període primitiu”, Estudis romànics, 3, 1951-52, 159-160.

5. F. Soldevila (ed.), Les quatre grans cròniques, Ed. Selecta, 2a ed., Barcelona, 1983, 405 (prólogo de Desclot); 706, 724, 748, 805 (en la obra de Muntaner).

6. M. Coll i Alentorn, "Les cròniques universals catalanes", Butlletí de la Reial Acadèmia de Bones Lletres de Barcelona, 34, 1972 (1971-1972), 43-50.

7. Para los matices y la periodización del humanismo en Cataluña, sigo a: L. Badia, De Bernat Metge a Joan Roís de Corella: estudis sobre la cultura literària de la tardor medieval catalana, Barcelona, 1988. Sobre Fernández de Heredia, véase: J. M. Nieto, "Las inquietudes historiográficas del Gran Maestre hospitalario Juan Fernández de Heredia (m. 1396): una aproximación de conjunto”, En la España Medieval, 22, 1999, 187-211.

8. A saber: Nino, Hércules, «Brutus, rey de Bretaña», Arbaus, Ciro, «Bellin y Breño», Artajerjes, Filipo, Alejandro, Pirro, Aníbal, los dos Escipiones, Sila, Pompeyo y César. 
res romanos a monarcas hispanos (Antonio, Augusto, Tiberio, Trajano, Severo, Constantino, Teodosio, Atila, Teodorico, Albuino, Heraclio, Carlos Martel, Carlomagno, Vespasiano, Tarik y Muza, Gengis Khan, Fernando III y Jaime I). Sus fuentes son Trogo Pompeyo (Justino), Plutarco, Tito Livio y diversos historiadores cristianos. Pero será en la Gran Crónica de Espanya, ${ }^{9}$ concretamente en su libro X («Historia romana desde la era hasta Marco Aurelio») donde Heredia aportará una nueva visión erudita de la Hispania clásica como claro precedente de Joan Margarit (c. 1421-1484) y su Paralipomenon Hispaniae. ${ }^{10}$

Parece que, desde su juventud, Joan Margarit, el futuro obispo de Girona y cardenal, hombre de confianza de Juan II de Aragón y Fernando el Católico, planeó la idea de investigar la antigüedad clásica de España. Será en último libro de sus "Cosas olvidadas de Hispania» (Paralipomenon Hispaniae) donde trata concretamente del edicto del censo universal que, supuestamente, Augusto establece durante su estancia en Tarraco. ${ }^{11}$

En los asuntos hispanos, Margarit no vacila en adoptar el punto de vista romano. Así, Viriato es un mero ladrón de caminos, las tribus españolas son desorganizadas, traidoras y sin auténticos líderes, aunque no están faltas de coraje. Esta parte de la obra, desde la conquista cartaginesa hasta el advenimiento de Augusto, proviene de autores latinos, en particular Tito Livio, César y Salustio, así como las biografías de Suetonio y Plutarco, aunque en algunos puntos los hechos están tan abreviados y mezclados que es difícil esclarecer si verdaderamente utilizó aquellas fuentes. Por ejemplo, para la vida de César siguió casi literalmente la biografía que de él hizo Petrarca, ${ }^{12}$ y para los hechos relacionados con Augusto utilizó una combinación de datos provenientes de Floro, Eutropio y Orosio.

La obra termina con la proclamación de la paz augustea y el nacimiento de Cristo, a pesar de que Margarit había anunciado su intención de prolongar el libro hasta los reinados de Arcadio y Honorio para unir la historia de los romanos con la de los godos. Según Margarit, el supuesto edicto del censo universal que aparece en el Evangelio de Lucas (2.17) se habría hecho durante la estancia de Augusto en Tarraco, aunque su promulgación se realizase algunos años después. Para defender su postura, Margarit no duda en afirmar que en el edicto constaba «Datum Tarraconae» según referían «maioribus nostris traditum in Romanis annalibus». ${ }^{13}$

Más que Augusto, las dos figuras que interesaron a Margarit como modelos de virtud política y moral, igual que a los humanistas italianos del momento, fueron Escipión el Africano y Julio César. ${ }^{14}$ No obstante, en el Paralipomenon, Augusto destaca no como figura

9. R. af Geijerstam, "Un esbozo de la Grant Crónica de Espanya de Juan Fernández Heredia”, Archivo de filología aragonesa, 52-53, 1996-1997, 267-294.

10. R. B. Tate, Joan Margarit i Pau, cardenal i bisbe de Girona: la seva vida i les seves obres, Barcelona, 1976; L. Lucero, "Joan Margarit, l' humanista”, Revista de Girona, 238, 2006, 68-73.

11. R. B. Tate, "El manuscrit i les fonts del Paralipomenon Hispaniae”, Estudis Romànics, 1957, 4 (19531954), 117-120.

12. R. B. Tate, “El manuscrit..., op. cit., 126-129.

13. J. Margarit, Episcopi gerundensis paralipomenon Hispaniae, haeredes Antonii Nebrissensis, Granada 1545, cap. X, fol. 77r.

14. R. B. Tate, "El manuscrit... op. cit., 131-132. 
histórica por ella misma sino más bien por el significado de su obra unificadora, presagio de la unificación que se alcanzaría siglos más tarde con la unión entre Fernando e Isabel, añadiendo que: «ipsa coniugali copula, utriusque Hispaniae Citerioris et Ulterioris unionem fecistis. Quae a Romanorum et Gothorum temporibus semper divisa nunquam sub eodem imperio perstiterut.» ${ }^{15}$

\section{Augusto en la periferia historiográfica (siglos XV-XVII)}

Fuera de los círculos humanistas de la corte catalano-aragonesa, Augusto y la época romana en general tenían un papel muy limitado en las historias patrocinadas por la pequeña nobleza. Un ejemplo paradigmático es el de Pere Tomic, caballero al servicio de la familia de Pinós. En su Històries e conquestes dels reis d'Aragó e comtes de Barcelona (1438), atribuye la fundación y poblamiento de Zaragoza a Julio César (no a Augusto), quien la habría puesto bajo el gobierno de Cornelio, barón romano, «e de aquell temps ença son en Arago lo linatge dels Cornells, que vuy hi son». ${ }^{16}$

Aunque con más erudición, un siglo después el cronista valenciano Pedro Antonio Beuter, en su Primera part de la història de València que tracta de les Antiguitats de Espanya y fundació de València (1538), repetía en el fondo los mismos argumentos, corrigiendo algunos equívocos pero añadiendo otros. En el capítulo trece (De la succesió dels emperadors aprés de Júlio César fins al Temps dels godos. Y la predicació de la sancta fe en Espanya y Valéncia) insistía de nuevo en el argumento de relacionar antiguas fundaciones romanas con familias de rancio abolengo:

Succehí a Júlio Octaviano Augusto. Aquest, perqué acabá de subjugar y pacificar a Spanya del tot, reedificà la ciutat de Saldívia en la ribera de Ebro y posà-li nom Çaragoça del seu nom. Com diu lo Plini, quasi Cesàrea Augusta. Edificada que fon, la poblà de molts nobles romans y entre.ls altres, de la família dels Cornèlios, de hon vingueren també los Cornèlios que en València foren, de qui fa memòria la pedra que hui està en lo Almudí de València escrita a Cornèlia, d'esta forma: [C] ORNELIAE / CIYCENI / AN. XVI ${ }^{17}$ D'estos també vingueren los Cornells que són en Aragó y aprés vengueren a València, salvant-se en temps dels moros en les muntanyes, com se dirà per avant, segons alguns. ${ }^{18}$

15.J. Margarit, Episcopi gerundensis paralipomenon Hispaniae, haeredes Antonii Nebrissensis, Granada, 1545, fol. 1r. Sobre los debates en torno a la traducción de la dedicatoria de Margarit, véase: L. Lucero, "Joan Margarit, Fidel Fita i Robert B. Tate: la dedicatòria del Paralipomenon Hispaniae”, Estudi General, 21, 2001, 465-473.

16. P. Tomic, Histories e conquestas de Cathalunya, Joan Rosembach, Barcelona, 1495, fol., 7v. La Casa de los Cornel (o Corneles) fue una de las casas más importantes de la nobleza medieval aragonesa. Véase: G. García Ciprés, “Los Cornel”, Linajes de Aragón, VII-6, 1916, 101-105.

17. «A Cornelia Glice, de 16 años». Inscripción sepulcral perdida, siglo II d.C. La primera noticia la da Beuter: CIL II 3759; CIL II ${ }^{2}$ 14,55.

18. P. A. Beuter, Primera part de la història de València, que tracta de les antiquitats d'Espanya y fundació de València, ab tot lo discurs fins al temps que lo ínclit rey don Jaume Primer la conquistà, Joan Mei, Valencia, 
En el medio local, como no podía der de otro modo, es en Tarragona donde encontramos el mayor interés por recuperar la figura de Augusto. En su Libro de las grandezas y cosas memorables de la metropolitana, insigne y famosa ciudad de Tarragona (1572), ${ }^{19}$ Lluís Pons d'Icard recoge la estancia del emperador en Tarraco y las embajadas que allí recibió. Sus principales fuentes son Orosio y los epítomes de Floro, pero también Margarit, obispo de Girona, Antonio de Guevara (Vida del emperador Adriano, 1539) y Florián de Ocampo. Pons d'Icard trata de la relación de Augusto con algunos monumentos de Tarragona aún visibles en su época, en especial con el llamado Palacio de Augusto (conocido también como Pretorio o «Castillo de Pilatos»). ${ }^{20}$ Según él, en este palacio se habría proclamado el censo que aparece mencionado en el evangelio de Lucas (2.1-7). Siguiendo a Orosio y a Alonso Venero (Enchiridion de los tiempos, 1545), Pons cuenta que tras las guerras cántabras se vería cumplida la profecía según la cual Cristo nacería en tiempos de paz universal. Donde concentra más sus energías es en demostrar que el edicto censal de Augusto fue hecho desde el Palacio de Augusto en Tarraco. Este hecho, siguiendo a Margarit, habría dado inicio a la llamada Era hispánica. El problema de la discordancia de fechas entre la estancia de Augusto en Tarraco (26-25 a.C.) y el censo de Judea (6 d.C., según Flavio Josefo, $A I .18,1)$, lo salva con el argumento de que la aplicación del censo, supuestamente universal, fue suspendida durante veintiséis años a causa de algunas revueltas en Galia y Germania. ${ }^{21}$

Los temas fijados por los historiadores del siglo XVI, provenientes tanto de las recuperadas fuentes clásicas como de su interés por relacionarlas con las antigüedades locales, se repiten en el siglo del barroco. ${ }^{22}$ Así, Antoni Viladamor (1523-1585), archivero y secretario real, en su Història general de Catalunya (c. 1585) ${ }^{23}$ entra a discutir de nuevo si Augusto proclamó el censo universal desde Tarraco. Recoge en este sentido la opinión de Margarit y los argumentos contrarios de Ambrosio de Morales. Viladamor defiende, como Margarit, que el edicto se realizó mientras Augusto residía en Tarraco, aunque se ejecutase algunos años después, y añade en tono ofendido no entender cómo Morales le negaba tal honor a Cataluña, ${ }^{24}$ apuntando: «la qual, com a cathalà, no puch dexar de sentir y dir que, si fóra scrit de qualsevol

1538 , fol. $47 \mathrm{v}$.

19. Editada, en castellano, en Lleida por P. de Robles y J. Villanueva, bajo el patrocinio del humanista A. Agustín. El manuscrito original, en catalán, ha sido editado por E. Duran, Lluís Pons d'Icard i el 'Llibre de les grandeses de Tarragona, Barcelona, 1984.

20. Cap. 28 «Del palacio que dizen de Cesar Augusto que estaba delante del circo» (fol. 164r-167v).

21. Cap. 31 «De cómo salió del dicho palacio el edicto o mandato que pone san Lucas en el evangelio, que Cesar Augusto mandó hazer para que se descriviessen todos los del mundo» (fol. 182r-187v).

22. Sobre este período véase: X. Baró, La historiografia catalana en el segle del Barroc (1585-1709), Publicacions de l'Abadia de Montserrat, Barcelona, 2009.

23. A. Viladamor, Història general de Catalunya (edición crítica de Eulàlia Miralles), Pagès editors, Barcelona 2007. Obra inacabada e inédita, que abarca desde los orígenes hasta la conquista musulmana del 714. Sobre Viladamor, véase: E. Miralles, "Antoni Viladamor i la Història general de Catalunya: la relació amb els seus coetanis i la recepció de l'obra fins al segle XIX”, Manuscrits, 40, 2000, 99-116.

24. «per lo que no puch crèurer no aparega mal als lectors desapassionats, de qualsevol nació que sían, de que en una cosa tant aprovada en totas las tronas y scholas, no sols de Espanya però de las altras nations, que 
ciutat, terra o lloch de Castella, que ell ho haguera sforçat, y que per ser llaor sola de nostra Cathaluña la ha volguda posar en dubte. Lo que sper no serà part per haver de ofuscar lo que en totes parts està tant admès.» ${ }^{25}$

El mismo tono reivindicativo de las tradiciones propias frente al olvido, por no llamarlo desprecio, de los historiadores de la corte, lo encontramos en Jeroni Pujades (1568-1635) y su Crònica universal del Principat de Catalunya (1609). ${ }^{26}$ En el libro III, capítulo 91, trata de "Cómo Octaviano edificó un palacio, é hizo el edicto en Tarragona, y recibió embajadores de la India». Aquí Pujades recoge las objeciones de Viladamor a Ambrosio de Morales sobre el edicto del censo universal. En los capítulos siguientes (92-94) añade a los datos de las fuentes clásicas una serie de suposiciones derivadas de la toponimia, la epigrafía y la numismática con el único propósito de ampliar las actuaciones de Augusto durante su estancia en estas tierras. Su manera de argumentar siempre es la misma:

Succehiren en Cathalunya dins lo temps Octavià estiguè en ella algunes coses, que per no tenir any cert de aquellas ... les quals nos poden dexar en silenci. Y la primera es que en lo temps estiguè Octavià en Tarragona, no deguè pasar tot lo temps sens venir à la ciutat y partides de Barcelona. Qua à be fins vuy no haja trobat auctor, queu diga expressament. ${ }^{27}$

En el siglo XVII observamos que, en relación a Roma y la obra de Augusto, la atención de los cronistas catalanes va dejando de lado Tarragona para focalizar su atención en Barcelona. Lo hemos observado en Pujades y es más acentuado aún en la Noticia Universal de Cataluña (1640) de Francesc Martí i Viladamor (1616-1687), ${ }^{28}$ escrita a inicios de la sublevación de Cataluña (Guerra dels Segadors). Martí i Viladamor fue fiscal de la Batllia General de Cataluña y uno de los enviados al Congreso de Münster en 1646 para negociar la paz con el Reino de Francia. A su regreso a Cataluña se le desposeyó de sus cargos acusado de traición y, en 1652, pasó a Francia bajo la protección de Pierre de Marca, quien había sido el enviado del rey Luís XIV durante la administración francesa de Cataluña y autor de la documentadísima Marca hispanica sive limes hispanicus (1668). ${ }^{29}$ En su Noticia Universal de Cataluña Martí Viladamor advierte que:

ell la haja volguda reprovar ab conjecturas tant poch fundadas y llevar a Cathalunya una cosa tant cèlebre $y$ sonada» (A. Viladamor, op. cit., vol. II, cap 54, frag. 110-115).

25. A. Viladamor, op. cit., vol. II, cap 54, frag. 115-120.

26. J. Pujades, Cronica universal del Principat de Cathalunya, Barcelona, 1609. Sobre Pujades, véase: E. Miralles, "La crónica universal del principado de Cataluña de Jeroni Pujades, una obra interpolada?", Llengua i literatura: Revista anual de la Societat Catalana de Llengua i literatura, 13, 2002, 223-272.

27. J. Pujades, op. cit., tomo 1, fols. $142 \mathrm{v}$.

28. X. Torres (ed.), Escrits politics del segle XVII. Tom I: Noticia Universal de Cataluña, de Francesc Martí Viladamor, Vic 1995. Sobre M. Viladamor, véase: J. Antón y M. Jiménez, "Francisco Martí i Viladamor: un pro-francés durante la Guerra dels Segadors”, Manuscrits, 9, 1991, 289-304.

29. Esto explicaría, por ejemplo, que en el Salon de Mercure de Versailles, Jean-Baptiste de Champaigne (1631-1681) representase al emperador Augusto en Tarraco recibiendo la embajada de la India (c. 1672, 
Nunca perdió Cataluña con permanencia su libertad, aunque estuvo sujeta al dominio de los griegos (...) hasta que reconoció el mundo la romana monarquía, en cuya edad, aunque los catalanes con la entrada de Marco Catón el Censorino perdieron por algún tiempo su libertad (...) Con todo, después que se sujetaron a los romanos gobernándose con sus leyes, luego gozaron de su misma libertad, como se infiere de lo que dice (...) que la ciudad de Barcelona, principal ciudad y cabeza de toda Cataluña, era inmune de los tributos del Imperio Romano, prerrogativa muy aventajada. Y aún corrieron más en la romana monarquía las excelencias de Cataluña. Pues el emperador Augusto César hizo a dicha ciudad de Barcelona colonia romana, nombrándola de su nombre colonia Iulia Augusta, como lo advierte Antonio Agustino. ${ }^{30}$

El mismo tono reivindicativo lo encontramos en la obra que cierra el siglo, escrita durante la Guerra de Sucesión Española, los Anales de Cataluña (1709) del austracista Narcís Feliu de la Penya (1642-1712). ${ }^{31}$ El título del capítulo 13 (tomo 1, libro 5) no lleva a engaño sobre su contenido:

Reside en Tarragona Octaviano. Confírmala colonia. Conságrale templo. Concluye la fábrica del Castillo Octaviano. Nombra Colonia a Barcelona, y municipio a Lérida. Firma, y decreta el edicto para registrarse el Orbe en Tarragona. Buélvese a Roma y naze nuestro Señor milagro en Gerona. ${ }^{32}$

\section{Augusto bajo la crítica (siglo XVIII)}

Durante la Ilustración, el espíritu crítico arrolla con todas las conjeturas que se habían ido acumulando sobre la estancia de Augusto en Tarraco y se vuelve al escueto relato de las fuentes clásicas. Jaume Caresmar (1717-1791), en su Disertación histórica sobre la antigua población de Cataluña en la Edad Media (escrita en 1780 pero no publicada hasta 1821) ${ }^{33}$ recuerda que Augusto dividió Hispania en tres provincias, haciendo de Tarragona metrópolis de la

núm. de inventario: INV18502230). Agradezco la noticia de esta pintura al profesor Pierre Cosme de la Universidad de Rouen.

30. X. Torres, Escrits polítics... op. cit., 48. La referencia a A. Agustín proviene de sus Diálogos de medallas, inscripciones y otras antigüedades, Felipe Mey, Tarragona 1587, 263-264.

31. F. de la Penya, Anales de Cataluña y epílogo breve de los progresos y famosos hechos de la nación catalana, de sus santos, reliquias, conventos y singulares grandezas, y de los más señalados y eminentes varones que en santidad, armas y letras han florecido desde la primera población de España año del mundo 1788, antes del nacimiento de Cristo 2174, y del diluvio 143, hasta el presente de 1709. Tomo primero. Contiene los sucesos desde la primera población de España hasta el año 1163. Joseph Llopis impr., Barcelona 1709. Sobre F. de la Penya, véase: J. Sobrequés, "Narcís Feliu de la Penya, cap a la història moderna", Butlletí de la Societat Catalana d'Estudis Històrics, 22, 2011, 65-91.

32. F. de la Penya, op. cit., tomo I, cap. 5, libro 12, 97.

33. J. Mercader (ed.), Jaume Caresmar, Carta al barón de La Linde, Centre d'Estudis Comarcals, Igualada, 1979. La obra está dedicada a Manuel de Terá, barón de La Linde, que a la sazón era el intendente general de Cataluña. Sobre Caresmar, véase: M. Garí, R. Masdéu y M. Urbina, "Jaume Caresmar. L'home i la seva obra", Manuscrits, 10, 1992, 331-371. 
Citerior. Rememora también que en el año 26 aC, durante las campañas contra los cántabros, enfermó y se retiró a Tarragona; que estando allí fue nombrado cónsul por octava y novena vez y recibió a los embajadores de la India y de Escitia. Sobre el polémico censo de todo el Imperio, Caresmar advierte que:

el edicto del encabezamiento universal de que habla el evangelista san Lucas y aunque el cardenal Margarit, obispo de Gerona, en su Paralipomenon de las cosas de España, y otros escritores catalanes dicen que lo expidió Augusto estando en Tarragona: pero esto no lo fundan en testimonio competente, ni estuvo en Tarragona Augusto después del año 25 antes de Cristo, y es seguro que no pasarían veinticinco años desde la expedición del edicto a su publicación y ejecución. ${ }^{34}$

El erudito Caresmar, monje premonstracense del monasterio de Bellpuig de les Avellanes (Os de Balaguer), miembro de la Acadèmia de Bones Lletres de Barcelona y de la Real Academia de la Historia, da así el asunto del censo por zanjado.

\section{Augusto y el catalanismo (siglo XIX)}

Las simples recopilaciones de datos fidedignos ya no satisfacían al nuevo perfil de historiador surgido después de las Guerras Napoleónicas. Al entrar en el nuevo siglo, se hizo evidente que la puerta se había cerrado en falso, pues Víctor Balaguer (1824-1901), en su Historia de Cataluña y de la Corona de Aragón (Barcelona, 1860-1863) ${ }^{35}$ repite las mismas noticias sobre Augusto que ya recogió Pujades a principios del siglo XVII, pero con un concepto de nación marcadamente romántico. Balaguer habla directamente de «guerra de la independencia ibérica» (ibérica en el sentido de toda la Península), cuyos últimos defensores habrían sido en Cataluña los ceretanos y en la otra parte de España los cántabros y astures. ${ }^{36}$ Pero Augusto no tiene el protagonismo del que había gozado hasta entonces y tampoco el dominio romano habría supuesto la completa sumisión de los naturales del país, pues estos: "comunicaron a sus nuevos súbditos los catalanes, junto con sus leyes, sus ciencias, artes, idioma, usos y costumbres, y con ello se aumentó la población de este país, renaciendo la agricultura muy particularmente y colmándose un poco el pesar que sentían los naturales por la pérdida de su libertad, gracias a la apariencia de bienestar que les ofrecían las instituciones romanas». ${ }^{37}$

34. J. Mercader, op. cit., 68-69. Sobre Balaguer historiador, véase: R. Grau, "Les coordenades historiogràfiques de Víctor Balaguer", en M. Comas (ed.), Víctor Balaguer i el seu temps, Publicacions de l'Abadia de Montserrat, Barcelona 2004, 41-68.

35. V. Balaguer, Historia de Cataluña y de la corona de Aragón: escrita para darla a conocer al pueblo, recordándole los grandes hechos de sus ascendientes en virtud, patriotismo y armas, y para difundir entre todas las clases el amor al país y la memoria de sus glorias pasadas, Librería de Salvador Manero, Barcelona 1860-63.

36. V. Balaguer, op. cit., vol I, 53.

37. V. Balaguer, op. cit., vol. I, 67. 
Como reacción, Antoni de Bofarull (1821-1892), en su Historia crítica (civil y eclesiástica) de Cataluña (Barcelona, 1876-78) (3) $^{38}$ aunque tampoco da protagonismo especial a la figura de Augusto, sí, en cambio, ensalza la labor civilizadora de los romanos, cuyo régimen municipal, «introducido por Augusto», habría aportado más a favor de Roma y al futuro espíritu nacional que la violencia de los Escipiones. ${ }^{39}$ Así mismo, la época posterior a Augusto: "puede llamarse de transición entre el antiguo estado salvaje y la cultura romana, y entre las imperfecciones sociales del mundo romano y la civilización cristiana; remedio perfecto y verdadero, como divino y moral, a los males producidos hasta entonces por el dominio de la fuerza y por el loco desenfreno de las pasiones terrenas». ${ }^{40}$ Para Bofarull, la dominación romana, bajo cuya influencia la civilización de Roma se fue infiltrando en las costumbres de los habitantes bárbaros de la Península, acabó por infundirles verdadero espíritu romano, de manera que no se diferenciaban de los «demás súbditos de Roma», sino meramente por el país que ocupaban. ${ }^{41}$

Todo lo contrario de aquello que defenderá en un contexto político marcado aún por «La Gloriosa» (la Revolución de 1868) Antoni Aulèstia i Pijoan (1849-1908) en su Història de Catalunya (Barcelona, 1887-89). ${ }^{42}$ Para él:

Apagades per sempre les lluites de la independencia ibérica, s'escorra desde'l sigle primer de nostra Era la vida de Catalunya sots lo jou del Imperi. Mes no hem de considerar que aqueix jou fos una absorció completa de la naturalesa i modo d'ésser del poble indígena. Lo concepte del Estat que tenien los polítics romans era massa superior pera no respectar les costums y'l modo d'ésser de les regions que tenien verdader cràcter; arribant fins a deixar en moltes d'elles sos reys y sos particulars governs polithics, especialmente en temps de la república. ${ }^{43}$

Fijémonos en el detalle, Aulèstia alaba el respeto de los políticos romanos, especialmente en tiempos de la República, por las costumbres y la manera de ser de Cataluña. Y esto lo escribe después del fracaso de la Primera República y en plena Restauración borbónica. No deja de haber aquí ecos del federalismo pimargalliano, o más probablemente de Valentí Almirall.

38. A. de Bofarull, Historia crítica (civil y eclesiástica) de Cataluña, tip. de Juan Aleu y Fugarull, 9 vols., Barcelona 1876-78. Sobre Bofarull, véase: R. Grau Fernández, "El pensament històric de la dinastia Bofarull”, Barcelona quaderns d' història, 6, 2002, 121-138.

39. A. de Bofarull, op. cit, vol. I, 98.

40. A. de Bofarull, op. cit, vol. I, 100.

41. A. de Bofarull, op. cit, vol. I, 146.

42. A. Aulèstia i Pijoan, Història de Catalunya, Impremta La Renaixensa, Barcelona 1887-89. Sobre Aulèstia, véase: A. Gil Ambrona, "Antoni Aulèstia i Pijoan: Compromiso catalanista e Historia: una trayectoria de difícil equilibrio", Manuscrits, 11, 1993, 259-279.

43. A. Aulèstia i Pijoan, op. cit., vol I, 65-66. 


\section{Un Augusto «noucentista» (siglo XX)}

Cuando el catalanismo se convirtió en movimiento político de la mano de Prat de la Riba, adoptó la particular interpretación del clasicismo predicado por Eugeni d'Ors, según la cual la cultura catalana necesitaba recuperar sus raíces clásicas para convertirse en una sociedad plenamente moderna, europea y civilizada. Al nuevo movimiento cultural e ideológico D’Ors le puso por nombre «Noucentisme».

La interpretación noucentista de la nación catalana encontrará su desarrollo más brillante y completo en la Història de Catalunya (1934-35) ${ }^{44}$ de Ferran Soldevila (1864-1971) ${ }^{45}$. En el capítulo primero, bajo el título "La gestació de Catalunya», Soldevila se preguntaba «¿Què degué Catalunya a aquesta romanització?» y responde que ésta favoreció el proceso de unificación de las tierras catalanas, pues gracias a ella apareció por primera vez una entidad -el convento jurídico tarraconense- que, de una u otra forma, religaba y plasmaba Cataluña. ${ }^{46}$ Argumenta Soldevila que el culto al emperador deificado, que se encuentra, como culto local, en Tarragona, el año 25 aC, y como culto provincial el año 15, dio lugar a la reunión de las asambleas o concilios provinciales, a los cuales acudían los delegados (legati) de todas las comunidades rurales y urbanas. Añade que:

Les seves funcions, inicialment religioses, s'anaren ampliant, i els concilis pogueren presentar peticions a l'emperador mateix i fiscalitzar la gestió dels governadors. La reunió del concili era anual $i$ tenia lloc a Tarragona, capital de la província. No cal ponderar la importància d'aquestes assemblees, que relacionaven els pobles de la província, i que, un cop suplantada pel cristianisme la religió pagana, van perdre tot caràcter religiós i es van convertir en corporacions de l'administració

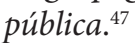

Interpretando estos concilios provinciales como si de unas proto-cortes se tratase, la historiografía noucentista instrumentalizó los referentes históricos sobre Augusto para ver en las instituciones romanas de la Tarraconense un embrión de la Generalitat de Catalunya.

Cerramos este artículo con una imagen de Augusto dirigiendo su Imperio desde una Tarraco idealizada, ennoblecida con monumentos imaginarios (fig. 1). Forma parte de un conjunto de 51 cromos de la colección Episodis historichs, obra del pintor y dibujante Joan Llaverias i Labró (1865-1938) que, dirigida a un público infantil, repasa los grandes momentos de la historia de Cataluña, en los que no podía faltar el episodio en el cual la catalana Tarraco fue capital del mundo.

44. F. Soldevila, Història de Catalunya, Ed. Alpha, Barcelona 1934-35.

45. Sobre Soldevila, véase: E. Pujol, "Ferran Soldevila i el cànon historiogràfic català", Butlletí de la Societat Catalana d'Estudis Històrics, 22, 2011, 235-246.

46. F. Soldevila, op. cit., vol I (segunda edición 1962), 15-16.

47. F. Soldevila, op. cit., vol I (segunda edición 1962), 17. 


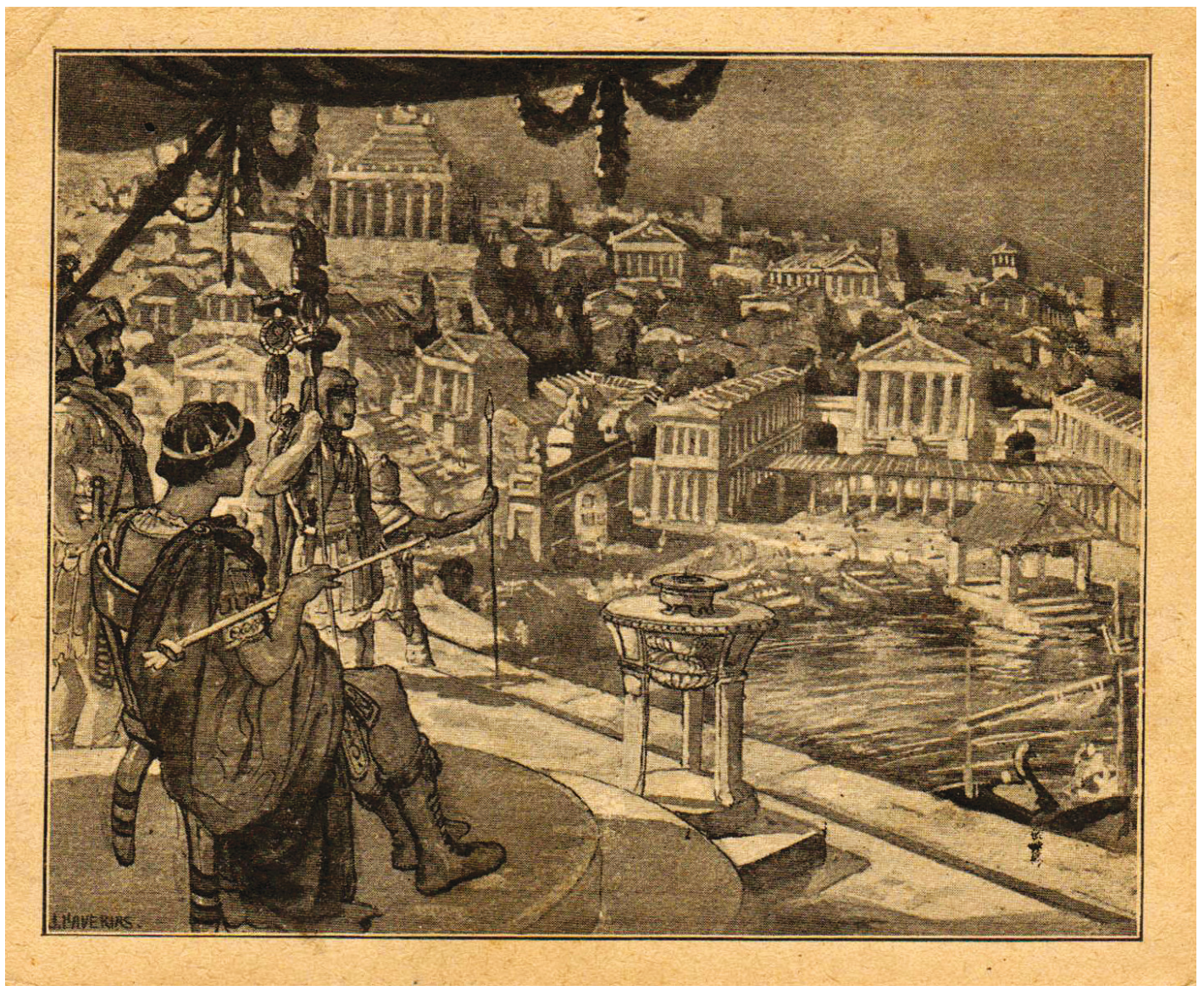

Fig 1. La colonia Tarraco (segle I abans de J.C). (1904).

Servicio de Arxivos Municipalse de Lloret de Mar - Fodo personal 605: Joan Llaveria, Episodis histórichs (sig. top. 66.195.9). 